\title{
Being a Woman \\ The Social Construction of \\ Menstruation Among Hmong Women in Australia
}

\section{Pranee Liamputtong}

\section{Introduction}

Women, Women ... Well! if you don't have menses then you will not be able to have children, but if you have your menses then you will be able to have children (Fieldnotes 1994)

Menstruation! People who are ignorant would say that it is a dirty thing, but it is the most important thing for you. If you don't have that you are not able to have children. If you don't have that you will not look healthy and it makes you look pale and unhealthy. If you have it you have no problems at all (Fieldnotes, 1997)

Menstruation is a universal physiological process in the lives of all women. But perceptions, meanings and practices related to it are not. As Buckley and Gottlieb (1988: 3) put it: 'While menstruation itself has at least a degree of biological regularity, its 
symbolic voicings and valences are strikingly variable, both crossculturally and within single cultures.' Menstruation, as such, is viewed and treated differently in different cultures. In most cases menstruation is seen as related to procreation; it gives women power to conceive babies. But at the same time menstruation is seen as producing 'potentially polluting substances' (Delaney 1988: 80) and can cause harm to others, particularly men. Due to this, 'taboos' about it exist in many cultures. Very often these taboos are imposed on women's lives with the purpose of safeguarding others. These taboos have been interpreted as oppressive to women (Buckley and Gottlieb 1988: 6).

However, this does not mean that all societies see menstruation as polluted and dangerous to others. Hence, a universal assumption about the existence of menstrual 'taboos' may be problematic for some cultural groups. Buckley and Gottlieb (1988: 7) have argued this in their critical analysis of theories of menstrual symbolism. They point out that what is commonly found is a wide range of 'rules for conduct regarding menstruation that bespeak quite different, even opposite, purposes and meanings'. In this chapter I will demonstrate that so-called menstrual 'taboos' do not really exist in Hmong culture even though women may feel embarrassed about their menstruation. There are, however, 'rules' which restrict women's bodies and behaviours. These restrictions function to control women's bodies for another purpose; that is, for procreation, rather than protecting men from being harmed by women's blood.

In this chapter, the experience of Hmong women is used as a paradigmatic case to analyse cultural interpretations of menstruation. ${ }^{1}$ I take Mary Douglas's (1966: 34) symbolic interpretation of purity perspective as a point of departure for my study, where she theorises that: 'all bodily emissions, even blood or pus from a wound, are sources of impurity'. Accordingly, menstrual blood, like certain other bodily substances, becomes polluting only when it departs from the bodily bounds of the natural order. As such, what is still bound within its body is not polluting. 


\section{The Hmong in Australia}

The Hmong in Australia come from Laos where they lived as hilltribes in mountainous areas. Involved in the fighting between the American forces and the Pathet Lao (the communist faction in the Lao civil war) the Hmong were forced to move from their homeland in the mountains and escape to Thailand. The United States accepted the majority as migrants. There are over 180,000 Hmong people in America at present (see also Adler 1995, Liamputtong Rice 2000). In Australia, the number is far less than in the United States (under 2,000). The main concentration of the Hmong in Australia in the past has been in Victoria, though there are Hmong in Tasmania and New South Wales and now the greatest number is in north Queensland (see Lee, this volume). In Victoria, the Hmong live in close-knit groups, mainly in high-rise public housing in and around the state capital, Melbourne (Liamputtong Rice 2000).

Hmong beliefs are animistic and based on ancestor worship. They believe in reincarnation - the rebirth cycle. Hmong descent is patrilineal and patrilocal. Family names follow the clan system. There are ten clans in Melbourne. The average Hmong family is large. Most Hmong women in the study described here have approximately four to six children and it is likely they will continue to have more. Traditionally, the Hmong put a high value on having many children, particularly boys, since they could help in farming and continue traditional practices such as worshipping ancestral spirits, caring for their parents in old age, and carrying on the clan name. Such traditional customs are still practiced. In general, the Hmong are much poorer than other Southeast Asian refugees. The majority of Hmong people are unemployed, lack formal education and are still learning English.

\section{The Study}

This chapter is based on research in Australia among Hmong women who are refugees from Southeast Asia, who have migrated to Australia since 1975 , but particularly in the last ten years. I conducted 
ethnographic interviews covering a number of issues concerning reproductive health, including the experience of childbirth, with 27 Hmong women in Melbourne. The demographic characteristics of Hmong women in this study are presented in Table 1.

The majority of the women had experienced childbirth while living in a refugee camp in Thailand as well as in hospitals in Melbourne. Older women were asked to participate so that I could learn more about Hmong cultural beliefs and practices. In addition, I interviewed several Hmong traditional healers (three shamans, two women herbalists and one magic healer) in order to obtain more in-depth details on traditional healing methods.

The women were initially recruited through a community centre they and their families frequently visited, and from the personal network of my bicultural research assistant who is a Hmong native-born woman. She has worked for and represented the Hmong community in Melbourne for more than ten years and she is well known and accepted by most Hmong in Melbourne. A 'snow ball' sampling technique was also used to recruit women into the study (Minichiello et al. 1995, Liamputtong Rice and Ezzy 1999; Ezzy 2002); that is, the women were asked to nominate or contact their friends or relatives who would be interested in participating in the study.

Entry into the community was sought from community leaders. I attended one of the community's fortnightly meetings and sought permission from the community leaders. Without their permission I would not have been able to conduct my fieldwork. The Hmong community was informed of my presence and the purpose of my research. In addition, I attended a Hmong women's Pap smear information day organised by a community health centre where a large number of Hmong attended. At the meeting I informed the women of my research and its purpose. I asked if the women would be willing to participate in the research project and if they could assist me. Most women agreed to help.

Women were contacted by telephone. Agreement to participate in the study was gained after information about the research and the nature of the woman's participation was clearly explained. Each woman was notified of the time needed for the 
interview. The date of the interview was then arranged to suit each participant. The women were individually interviewed in their own homes after informed consent was obtained. All interviews were conducted in the Hmong language by the author with the assistance of a bicultural research assistant.

Each interview was tape-recorded. The length of the interviews varied, depending on the women's responses. In general, each interview took between two and three hours. Most women were interviewed once. There were, however, a number of occasions when more information was needed, and those women were then visited for a second time, and in some cases a third time.

In addition, participant observation was used to observe and record Hmong cultural beliefs and practices and their experiences in Australia more fully. I attended a number of Hmong ceremonies and participated in Hmong activities. The main interviews and participant observation were conducted between May 1993 and July 1994. However, since the initial fieldwork I have revisited the community in order to obtain more up-to-date information and maintain contact with key informants, the most recent participant observation and several follow-up interviews were undertaken in 1999.

I situate my theoretical framework within the approach of phenomenology. The in-depth data concerning perceptions and experiences of menstruation was analysed using a thematic analysis methodology guided by phenomenology (Liamputtong Rice and Ezzy 1999, Ezzy 2002). Phenomenology, as Becker (1992: 7) argues, aims to interpret 'situations in the everyday world from the viewpoint of the experiencing person'. Phenomenology attempts to 'determine what an experience means for the persons who have had the experience and are able to provide a comprehensive description of it' (Moustakas 1994: 13). In this study, the interview transcripts were used to interpret how women described their meaning and experiences of menstruation in their everyday lives. Their responses were then organised into coherent themes (Liamputtong Rice and Ezzy 1999, Ezzy 2002), as presented in the following section. Verbatim quotations are used to illustrate responses on relevant themes. The women quoted are identified by pseudonyms. 
Table 1: Characteristics of Hmong women interviewed

\begin{tabular}{|c|c|c|c|}
\hline Characteristics & & No. & Percentage \\
\hline \multirow[t]{4}{*}{ Age } & $20-30$ & 9 & 33.3 \\
\hline & $31-40$ & 8 & 29.6 \\
\hline & $41-50$ & 4 & 14.8 \\
\hline & over 51 & 6 & 22.2 \\
\hline Religion & Animistic & 27 & 100.0 \\
\hline \multirow[t]{3}{*}{ Marital status } & Married & 21 & 77.7 \\
\hline & de facto & 1 & 3.7 \\
\hline & Widowed & 5 & 18.5 \\
\hline \multirow[t]{3}{*}{ Level of education } & None & 18 & 66.6 \\
\hline & Primary & 7 & 25.9 \\
\hline & Secondary & 2 & 7.4 \\
\hline \multirow{3}{*}{ Current activities } & Home duties & 17 & 62.9 \\
\hline & Learning English for migrants & 7 & 25.9 \\
\hline & Working & 3 & 11.1 \\
\hline \multirow[t]{4}{*}{ Number of children } & $1-3$ & 7 & 25.9 \\
\hline & $4-6$ & 15 & 55.5 \\
\hline & 7-9 & 1 & 3.7 \\
\hline & 10 and over & 4 & 14.8 \\
\hline \multirow{4}{*}{$\begin{array}{l}\text { No. of family } \\
\text { members living } \\
\text { in the house }\end{array}$} & $1-3$ & 2 & 7.4 \\
\hline & $4-6$ & 11 & 40.7 \\
\hline & $7-9$ & 10 & 37.0 \\
\hline & 10 and over & 4 & 14.8 \\
\hline \multirow{4}{*}{$\begin{array}{l}\text { Length of stay in } \\
\text { refugee camp in } \\
\text { Thailand (years) }\end{array}$} & $1-3$ & 6 & 22.2 \\
\hline & $4-6$ & 3 & 11.1 \\
\hline & $7-9$ & 6 & 22.2 \\
\hline & 10 and over & 12 & 44.4 \\
\hline \multirow{3}{*}{$\begin{array}{l}\text { No. of years in } \\
\text { Australia }\end{array}$} & $1-3$ & 6 & 22.2 \\
\hline & $4-6$ & 13 & 48.1 \\
\hline & 7 and over & 8 & 29.6 \\
\hline \multirow{4}{*}{$\begin{array}{l}\text { Experience of } \\
\text { childbirth }\end{array}$} & In Laos only & 5 & 18.5 \\
\hline & In Thailand and Australia & 15 & 55.5 \\
\hline & In Laos, Thailand and Australia & 2 & 7.4 \\
\hline & In Australia only & 5 & 18.5 \\
\hline \multirow[t]{2}{*}{ English Proficiency } & Poor & 23 & 85.2 \\
\hline & Good & 4 & 14.8 \\
\hline
\end{tabular}




\section{Menstruation: Being a Woman}

The Hmong recognise that menstruation is an essential part of being a woman. Being a woman means to menstruate. The term commonly used by the Hmong to mean menstruation is $u a p o j$ niam, which literally means 'being a woman'.

If you are a woman it must come. If you are a woman you must have menstruation. (Mai)

This 'woman-nature' is determined by a Hmong god who rules the Hmong world. A normal woman, therefore, must have menstruation.

The 'period' is a natural thing for women. It is god-given and you will only have it if you are a woman. (Blia)

Menarche marks the beginning of womanhood among the Hmong. This is referred to as nto nkauj nto niam, meaning that women have finished their childhood and reached womanhood or motherhood. It is believed that when a young girl commences her menstruation she is capable of producing children. Dia explained:

When the girl starts to have menses it means that she has reached motherhood ... Because when she has this she will be married and will be able to bear children. It means that you have the ability to conceive or bear children.

\section{Menstruation and Health}

At one level, menstruation is seen as 'bad' blood that must be expelled from the body. At another level, however, menstruation is believed to change the blood within the body. The circulation of 'bad' blood enables the renewal of the blood, which in turn will make a woman healthy.

People say that if you have menses it is good because you have it every month and that is when it washes out the bad blood. (Joua) 
The Hmong believe that women whose menstruation ceases for whatever reasons will be unhealthy. Women in this condition may become pale, skinny and eventually die.

When you have your menses it is good. If you don't have it then you are like a person who is very unhealthy. Because you don't have your menses you are very pale and look like a person who is always sick. (Neng)

The clotting of menstrual blood is, however, seen as most dangerous to women's health.

If you have clots and you don't have the menses anymore then you will die ... Like if your blood can't come out, it will clot inside your body and so you can't eat and become skinny and thus your blood inside your body will dry up and you will die. (Ntsi)

Dia told us about her relatives and acquaintances who had died from menstrual blood clotting.

If you don't have the blood you will become skinny and then you will die ... There are three people that I know who have died from blood clots. They became extremely skinny and their face was not normal; it became very yellow. They had no strength at all and became smaller and smaller and then died. Our [relative]'s first wife died of blood clots. My brother's eldest daughter had that and died too. The $[\mathrm{X}]$ family's aunt died of that too. I saw them with my own eyes.

\section{Menstruation, Pregnancy, and the Baby}

Menstruation is seen as closely associated with procreation. For women, without menstruation, they are unable to produce children. Xao remarked that:

For women it is a natural part of life and if you don't have it then you will be sick and look pale and just unhealthy. So you must look for medicines so that you can have it for good health and so that you can have children. 
When asked about the relationships between menstruation and pregnancy, women offered two answers. First, menstruation 'makes the baby'. This is why women stop having menstruation when they become pregnant.

People say that when you have no more menses it means that it has become the baby and that is why you don't have any menses ... Until you give birth to the baby and after one month you will see it again for one time, then no more. When the next baby is going to be conceived then you will see the menses again. (Dia)

Mai Koo used the metaphor of a protective dam to describe the relationship of menstruation to the baby.

I think that when you are pregnant, it will stay inside and not come out at all ... I think that when you conceive a baby your blood and water will make a dam for the baby; like a dam would be for the fish. When the baby is born then it will come out with the baby.

Secondly, women said that menstruation disappears during pregnancy because menstrual blood is used to feed the baby inside the womb.

Some women say that that is where the baby is going to grow from and that's why it stops and that menses becomes the baby's food. It may be like that because when you get pregnant you don't have that any more. (Mao)

\section{Good Menses and Bad Menses: Health and Fertility}

The Hmong distinguish between good menses and bad menses. The colour of the menstrual flow is used as an indicator of good or bad blood. It is believed that good menstrual blood must be bright red. If it is dark it means bad blood. Bright blood will make the woman healthy. By contrast, dark blood will make the woman pale and skinny; the indication of bad health. 
If you have menses which is no good, like it is not bright, then this means that there is a problem with your body and that is why you are pale. (Mai Koo)

The flow of blood is also used to identify good or bad menstruation. A moderate flow is believed to be best for any woman. A combination of light flow and dark colour indicates bad health. Mai Zong explained that:

For myself, if the blood comes a little bit at a time and black then it is no good. If your blood is no good then it will make you unhealthy. If that blood is very bright and good then it finishes quicker and you don't feel tired, only feel stronger.

The humoural quality of menstruation is also an identification of good or bad menses and closely related to fertility. This humoural quality is based on the hot/cold dichotomy, as found also in the Chinese medical system. It is believed that 'cold' menstruation contributes to infertility. Women were able to tell if their menstruation was warm or cold, as Dia related:

You can feel it when you have your menses from your body, if it feels cold, your menses is cold. Also when you wash your clothing the blood will be black. That means it is cold.

Good menstruation means good conception. Good menstruation does not cause health problems such as back and abdominal pains. Due to this, women who have good menses have the tendency to conceive easily.

The old people say that you must have good menses and then you do not have stomach or lower back pain for you to be able to conceive. (Ntsi)

The colour, the flow and the humoural quality of menstruation are also an indication of the capability to conceive. When asked under what circumstances women may conceive, a common answer given was as Nhia told us:

If your body is healthy and your menses flows properly, then your menses is bright and that is how you can have 
them [children]. But if your menses is not flowing properly then you will not be able to conceive.

Regularity of the 'period' is also believed to be an indication of good conception.

For good conception, the blood must be bright in colour. Also for those women who have irregular period they will have children very far apart; they will find it hard to conceive. (Nhia)

When women talk about infertility, very often they indicate menstrual colour and flow as its main cause, as Blia elaborated:

Periods vary from one person to person. It depends if they have always had only a little or a lot. If they have a little then they will have a little ... But [Y]'s wife told me that the reason why she can't conceive is because she has only a very small amount of period each time.

But menstruation with a heavy flow is believed to be the result of being 'hit' by spirits.

If you have too much menses then it is not good; small amount is better. A lot would mean that the spirit is trying to destroy your womb and that is why it has a lot of blood. (Dia)

\section{Menstruation: An Embarrassing Matter}

Despite the fact that menstruation is good for women's health and despite its importance for procreation, most women also see it as 'embarrassing'. This was reflected in interviews when I started to ask the women about menstruation. The following conversation illustrates this point.

Researcher: I would like to ask you about menstruation, is this okay?

Informant: What do you want to know about it?

Researcher: Well, anything that you can tell me, I think it is related to having a baby. 
Informant: Is it? We are to talk about your body having that dirty thing! Yes, you can, but what do you want to talk ... With the Hmong, it is the most embarrassing thing to talk about ... Yes, I am telling the truth, I became a shameful person because of my menstruation; it flowed too much. (Nhia)

When women no longer need to worry about the stain on their tia Hmong (Hmong skirt) which causes such great embarrassment, women feel somewhat relaxed about having no more menses. Dia said:

With the menses, Hmong in the villages have no underwear and no napkins so wherever they sat they will leave a mark. This is very embarrassing. Whenever the menses is due then you will worry a lot and feel scared that it will show. So when you don't have any more menses, you don't need to worry about it anymore.

The embarrassment was far greater for women in the past when there was the fear other people might be able to see a stain on their skirts or pants or even blood running down their legs.

I think that because it is unclean, it is unhygienic. In Laos there are lots of people and if you can't keep it clean it stains your clothes and you feel embarrassed towards other people like the men around you and your children and family. You will feel that they can see you. (Xao)

It must be noted that in Laos, Hmong women did not have access to sanitary pads like in Australia. Women did not have much to prevent the running of menstrual blood. In addition, the scarcity of materials sometimes prevented women using anything to wipe their blood away. If any sign of their menstruation was shown, women were criticised for not being able to hide their 'embarrassing' parts, even by other women. Dia remarked:

What can you do! If someone sees it and if these people like criticising others then they will say 'look at her she is having that thing'. So this will make you even more embarrassed. But some women will reply it is god-given 
to every woman, don't you say that to me. Sooner or later you will have that too'.

Men, particularly young men, would also talk about it if they saw women with any menstrual marks on their clothes. However, women also mentioned that despite this criticism, men would not choose any woman who was not menstruating for marriage, since they knew that such women would have difficulty in conceiving.

Men! If they see women having that, some younger ones will talk about it. But, like I said before, if you don't have it then no one will want to marry you. (Dia)

When you are menstruating the men will avoid you and they will also talk ... I think they think that it is dirty. (Xao)

Due to this embarrassment, all Hmong women who have reached menopause say that they feel much relieved. They also believe that the cessation of menstruation makes them become 'clean like men'.

When you are old and you don't have any more menstruation it is a good thing ... You will be just like a man. (Ntsi)

Blia, an older woman, told us about her embarrassment and bad experiences with her menstruation. She said that she sought herbal medicines to terminate her menstruation, which she succeeded in doing. And so now she is 'clean like the men'.

For me, I had bad menses and I hated it so much that is why I resorted to looking for medicines to get rid of it. I took medicines and so I am very clean like the men now ... I hated it so much that when it was gone I felt great. I was happy that I didn't have that anymore. I don't have to be embarrassed in front of other people any more. (Blia)

Those who have not reached the menopause have ambivalent feelings about menstruation. On the one hand, it is seen as essential for procreation. On the other hand, having it 
causes uncomfortable feelings. Worst of all, if it does not come it may mean death. Ntsi elaborated:

Being a woman, that is very dirty and if you don't have it then you may be afraid of dying and if you do have it, it is an uncomfortable thing to have ... The elderly say that if it just stops by itself then it may be a clot inside your body and that is why it can't flow and this can kill you ... So it is unclean but if you don't have it you may die too, and also it means that you can't have children.

\section{Dietary and Behavioural Restrictions}

While menstruating, Hmong women do not have to take precautions over their diet, except for foodstuffs which are extremely cold, such as icy cold water and ice. Women believe that drinking icy cold water will cause the blood to clot and this leads to health problems.

With food there is no restriction. Only that when you have the menses you should not drink very cold water because your blood will clot and that can make you sick. (Nhia)

When you have menses you should not eat ice. If you eat it then your body will not be able to rid of the blood. When you eat the cold thing into your body it will make the blood clot and make you sick; pain in the stomach and you get all sort of sickness and this is no good for you. (Va)

Several women, despite this, mentioned that they could drink cold water during menstruating. However, women who are likely to experience abdominal pain while menstruating will normally try to avoid it.

Some people say that they if have no pain in the stomach or anywhere else they can drink it. For the ones that are at a higher risk of having stomach pain don't ... The ones that don't drink are the ones that have strong pain. Every time they have their menses they will lie down and at the 
end of it they will be very skinny. These are the ones that will not drink cold water. (Xao)

The Hmong do not have many behavioural restrictions during the menstruating period. Women say they can perform their usual tasks and have contact with others in the community.

When you have your menses you don't need to watch out for anything. You are allowed to do most things you want to ... For me I never stop doing any housework or other things. (Der)

However, there are restrictions which women are well aware of. These include not crossing over rivers, not washing their bodies or their menstrually marked clothes in rivers or dams, and not throwing the water used to wash off their menstrual blood into rivers. It is believed that these actions will offend nature spirits who will become angry and strike them. This in turn leads to miscarriage and infertility. Yee explained that:

In Laos the old people would tell you that if when you have your menses and you go to wash your body in the river, the spirits there are able to trace you and hit you. If the spirits hit you and if you get pregnant, the spirits will damage it and it will come out [miscarry].

Mai, too, elaborated that:

When you have your menses you should not go to wash these clothings in a river. When you have just grown up you do not know this so when you have your first menses your are very embarrassed about it so you go to wash your clothing in a river which is man-made and you must not throw the dirty water back into the river. If you wash your clothes and throw the water back into the river the spirit can 'hit' you and this will cause you to be sick. If you wash you must wash it and throw it into the soil. If you throw it into the river it will make you sick and when you get married it will cause you to not have any children and it is very hard to fix. You may conceive but it is only after a long time of healing that you can conceive. 
While menstruating, Hmong women totally avoid sexual intercourse. Their main reason for this is that the men do not like it because it is dirty. For the women's part, they feel embarrassed about letting their husbands see their menstruation. They therefore try to stay away from their husbands and most men understand this behaviour and will not insist on sexual intercourse during this period.

When you have menses you can't have sex with your husband because when it is like that it is very dirty ... For us, we don't like it because when you have that [menses] you are very embarrassed so you don't even sleep near your man. (Mai)

\section{Menstruation: Seeking Healing}

If there is pain associated with menstruation then you have to ua neeb saib to see what happens. And if the outcome of that is there is nothing wrong then you can just use the herbs to wash your body so the clots will dissolve and so you won't have any more pain ... [But] if you are hit by spirits you have to ua neeb kho to separate the spirit. (Mai Koo) ${ }^{2}$

As this quotation shows, when women have difficulties with their menstruation, there are remedies Hmong women can seek to relieve their symptoms of ill health. There are two main healing methods most Hmong use.

\section{Hmong Herbs}

When a woman's menstruation does not flow properly or ceases, Hmong women resort to Hmong green herbs.

When it does not flow properly then you use Hmong herbs to wash out the bad blood and the clotted blood. After this you will be back to normal ... If the bad blood remains inside the body this will make you have stomach pain. (Va) 
Women say that these medicines are wild plants. Some herbs are in root form but they may also be derived from the leaves or stems of a plant. Only those who are knowledgeable about this are able to gather them, and most of these people are old women.

Very often, however, women must ask a female herbal specialist to prepare herbs for them. The herbalist prepares a herbal concoction for them to drink, usually for three nights and once each night, and then their menstruation will flow properly.

If the menses does not flow properly then you have to go and $f i v$ [ask] medicine from a kws tshuaj [herbalist] to give medicine for you to drink to regulate your body so that you will have the menses again. You will have to take it only two to three times before you will get better. (Nhia)

The herbal specialist must be asked for assistance and during this process, an agreed fee is negotiated. If the treatment is not successful, there is no fee to be paid. However, if the patient recovers, she must pay the agreed fee.

If your menses is clotted you have to $f i v$ [ask] someone before they will give you any medicine. They will give you grown herbs and whatever they know they will use to help you. You will take the medicine and if it helps you then you will pay them the agreed amount. (Dia)

The fee charged by the herbalist is a sign of respect to those who have passed the knowledge to her. Without it, she will lose her healing ability. More importantly, if she persists in giving out such acquired knowledge without a fee, she may become ill herself and eventually die, or her herbs may become ineffective.

\section{Txiv Neeb (The Shaman) and Ua Neeb (Shamanic Rituals)}

If it is suspected that the menstrual pain of women is caused by being struck by spirits which are making them bleed heavily, a shaman must be asked to help. 
If you know that this is what has happened [being struck by spirits] then you must go to see the shaman and ask him to fix you. It is only a txiv neeb who can help you. (Neng)

To ask a shaman to assist in alleviating menstrual pain, a woman must go to the shaman's house where his or her altar is located, and formally request for help. Once this is done, the shaman first holds a ritual to diagnose the cause of the woman's abdominal pain (ua neeb saib). If it is diagnosed that she has been 'struck' by spirits, the shaman then holds another ritual to negotiate with the spirits and perhaps bribe them to leave the woman in peace ( ua neeb cais). Traditionally, the spirits will be offered a sacrificed pig and some 'silver-and-gold' money (in paper form). If the spirits are malicious and do not wish to leave the woman, the shaman will have to invoke his spirit assistants to negotiate with them. Usually the evil spirits will be defeated and eventually agree not to interfere with the woman's body. When her menstrual pain ceases, the shaman must then perform the last ritual, called ua neeb kho (the healing ritual). Traditionally, after the healing ceremony, the shaman must be offered a sum of money, a bunch of incense sticks, 'silver-and-gold' money and a live chicken as a payment for his service.

Nevertheless, the Hmong may try both healing methods when a woman does not recover easily. The following quotation from Mai illustrates this succinctly.

My friend and I went to swim in a river and my friend was menstruating. She washed her clothes there and since then she was sick very often. Whenever she got her menses she would be in bed for three to four days and she was very pale. The family ua neeb for her a lot of times and they looked for medicines for her too. After that she was able to get a bit fatter [healthier]. Then we came here [Australia] and now I don't know if she is able to have children or not. She is still in Na Po Camp in Thailand. 


\section{Discussion and Conclusion}

In many societies menstruation is perceived as 'pollution' because it is associated with dirt, mess and uncleanliness (Good 1980, Furth and Ch'en 1992, Rozario 1992, Prendergast 1994, Thuren 1994, Britton 1996). Good (1980: 149), for example, points out that in Iran 'menstrual blood (and the blood of childbirth) is not only physically polluting to the body, but is also ritually polluting. Menstrual blood is one of ten or 12 categories of nejasat, items which are ritually unclean, including faeces, urine, and the sweat of sexual exertion.' This uncleanliness of menstruation is similar to other forms of physical 'dirt' (like saliva or semen) which cross a bodily boundary. Hence, menstruation is symbolic 'matter out of place' (Douglas 1966). As such it becomes a 'pollutant' which is thought of as dangerous to social order. Due to this, rules or taboos commonly exist which are thought to protect human beings from the dangers of women's menstruation. Often menstruating women are 'excluded' from normal social activities such as cooking and looking for food. Britton (1996) and Buckley and Gottlieb (1988) point out that such seclusion of menstruating women has often been presented in negative terms; very often as oppressive to women. But feminist anthropologists have also pointed to the positive functions of women's seclusion or exclusion (see Rosaldo 1974, Patterson 1986, Gottlieb 1988, Martin 1992, Sobo 1992, for example). Rosaldo (1974: 38) argues that 'pollution beliefs can provide grounds for solidarity among women'. Women's seclusion in menstrual huts, for example, can provide a form of sanctuary for women. Patterson (1986: 490) contends that most of the women on Mogmog Island in the Pacific atoll of Ulithi in fact enjoy the break from their normal routines and 'spend the time happily talking or weaving. Their place of seclusion, the 'women's house', serves as a community centre for them.

In many societies, too, menstruating women are not allowed to have contact with their men for fear of contaminating or killing them. Sobo (1992: 116), in her writing about menstruation in Jamaica, for example, points out that women who wish to secure the love and money of men will use their menstrual 
blood in cooking as a way to 'tie' the men to themselves. Here women's intention to 'tie' men to them is 'central to menstruating women's "unclean" state'.

But, as Buckley and Gottlieb (1988) argue, not all cultures have menstrual taboos and in some cultures there exists a belief in the positive powers of menstruation, besides its pollution (compare Douglas 1966). Kuper (1947: 107) pointed out a long time ago: 'in certain situations ... menstrual blood is not destructive, but is considered a life symbol or rather a life force'. In this chapter I have demonstrated that the notion of menstrual taboo does not really exist in Hmong culture. The Hmong belief that menstrual blood turns to nourish the foetus during pregnancy well illustrates this point. Similarly, in Sri Lanka, although there is a belief that menstrual blood is extremely polluted, the blood which goes to the baby is seen as beneficial (McGilvray 1982). The women in McGilvray's study believed that menstruation blood stops during pregnancy because the blood goes to nourish the baby. Good (1980: 150) points out a similar belief among women in Iran. Despite menstrual blood being seen as polluting, the potent quality of this blood is also seen as an essential element in reproduction. Women believe that menstrual blood turns into food for the baby during pregnancy. Delaney's (1988) study points to the same belief among Turkish women.

If we accept Douglas's (1966) symbolic interpretation as an explanation of this, we may see that menstrual blood, like certain other bodily substances, becomes polluting only when it leaves the natural bounds of the body. Hence, what is still bound within its body is not necessarily polluting, but potent. This interpretation is applicable to the Hmong women's explanation of menstrual blood as a substance which makes and feed the foetus during pregnancy. And this perhaps explains why menstruation, among Hmong women, is not seen as so 'polluting' as in many other cultures.

In Hmong culture there is no belief that menstrual blood may harm men, as there is in many other cultures, including the Thai and Lao. But nevertheless there are social restrictions which are imposed on menstruating women. Most of these are related to beliefs in the fertility of women; that is, they serve to ensure that 
women will be able to produce children. This can be seen from beliefs that a menstruating woman should not consume 'cold' food since it will make the blood congeal and causes ill health, and that menstruating women should not cross a river or wash their menstrual blood in a river, as the spirits may trace them through the smell of the blood and cause miscarriage and infertility. In this sense, as Gottlieb (1988: 74) argues, menstruation can be seen as 'a symbol of fertility, or life', not necessarily a polluting process.

In Hmong culture, menstruation is seen as an essential part of womanhood. This is due to its ability to enable procreation; as Gottlieb (1988: 64) puts it, menstruation 'embodies a symbolic principle that makes possible human fertility in the form of babies'. Procreation is believed to be an essential part of Hmong women's lives, which in turn is essential to the reproduction of Hmong society. But just why are procreation and the ability to produce children so important and valued? Taking a 'social structural perspective', Inhorn (1996) argues that children are important for three main reasons. First, children are necessary in order to ensure the survival of their parents and families. Second, in most patriarchal societies children are the only 'valuable power resource' for their mothers. Hence, having children can improve the status of women. Third, children are needed for the continuation of the society itself.

In Hmong culture, children are necessary for one's wellbeing, not only in this life but also in the afterlife. This ensures the continuation of the family, lineage and clan. Without children, neither Hmong men nor women are perceived as complete. While Hmong girls and women do not have equal social or familial status to Hmong boys and men, their status changes when they marry and are able to bear a child. The birth of the first child brings prestige to a Hmong woman. Women gain respect and status when they produce children (Liamputtong 2002; Liamputtong Rice 1995, 1998, 2000; Symonds 1991, 1996). All these cultural expectations make menstruation an essential part of women's lives.

In conclusion, this study has provided readers with a cultural perspective on menstruation practices and beliefs among Hmong women now living in Australia. As Layne (1990: 70) has 
argued, 'the anthropological approach, with its emphasis on the cultural construction of meanings and special understanding of ritual process' provides a crucial dimension for research into women and reproduction. If we are to truly understand the rich reality of women's lives, we must see menstruation within the context of culture. This is particularly so in Australian society where the cultural diversity of immigrant women is so great.

\section{Acknowledgements}

I am indebted to Hmong women for their time and knowledge given to me during my fieldwork and afterwards. I am grateful to Blia Ly, my bicultural research assistant who assisted me during the fieldwork and subsequently in the process of analysis.

\section{Footnotes}

${ }^{1}$ This chapter is a revised and edited version of the chapter on menstruation in Liamputtong Rice (2000).

${ }^{2}$ Ua neeb saib and ua neeb kho are two parts of the shamanic healing session. See below. 